\title{
AMADO ALONSO (1896-1952) Y JOSÉ F. MONTESINOS (1897-1972)
}

Francisco ABAD

UNED

A la memoria de Cristina Grau

\section{RESUMEN}

Este artículo esboza la trayectoria intelectual que cumplieron en filología Amado Alonso y José Fernández Montesinos, y apunta asimismo cómo mantuvieron criterios críticos-literarios contrarios aunque no contradictorios.

\section{CUATRO CENTENARIOS}

Amado Alonso y Salvador Fernández Ramírez nacieron en 1896; José Fernández Montesinos lo hizo en 1897, y Dámaso Alonso en 1898: se cumplen ahora por tanto cien años de estos nacimientos. Estamos ante autores pertenecientes al grupo que se conoce como «generación del 27», y además se trata en este caso de estudiosos vinculados a Menéndez Pidal y que se adscriben así a la «escuela española» de filología o escuela pidalina. Los Alonso, Salvador Fernández y José F. Montesinos forman parte del grupo de discípulos directos e inmediatos de don Ramón, y forman con él y con otros autores la escuela pidalina o «escuela española» propiamente dicha.

Se cumple ahora el primer centenario de los cuatro, y aunque no hubiera hecho falta el motivo, a propósito de este centenario nos vamos a referir a dos de ellos, dejando de momento a don Dámaso para tratarlo separadamente. 
Amado Alonso tuvo una vida corta, pero fue estudioso de gran afán en cuya trayectoria de autor se observan bien los sucesivos problemas intelectuales a los que atendio. Distinguimos hasta seis motivos temáticos que resultaron de su interés, el primero de los cuales fue la dialectología hispanoamericana.

Efectivamente Amado public6 por una parte volúmenes como Problemas de dialectología hispanoamericana (1930), El problema de la lengua en América (1935), La Argentina y la nivelación del idioma (1943), y Estudios lingüisticos. Temas hispanoamericanos (tercera ed. en 1967); de hecho durante toda su vida se dedico a la geografía fonética, y de esta manera sus respectivas contribuciones a los Homenajes a Menéndez Pidal en 1925 y 1951, prácticamente abren y cierran una trayectoria de estudioso dedicado a la dialectología fonética en España y en América: ambas aportaciones se unen armoniosamente en la falta de solución de continuidad de los Estudios lingüisticos mencionados.

En los años treinta sobre todo Amado escribió además de Gramática: empezó con las tres monografías de «semiología y estilística» (del artículo, el diminutivo, y las construcciones con verbos de movimiento), y luego hizo los dos pequeños tomos de la Gramática Castellana.

Por semiología entendía nuestro autor el análisis de la significación lógica, mientras estilistica era el estudio de las sustancias afectivas, imaginativas y activas: se trataba de «estudiar en las expresiones y en las categorías gramaticales la totalidad de sus contenidos", contenidos que son lógicos, o afectivos, etc. Así se manifestaba Amado, y por ello entendía que en su trabajo hacía a la vez «gramática y estilística».

Como es sabido nuestro autor glosó hacia el final de su vida la Gramática de Bello, pero ya decimos que lo fundamental de su producción en esta temática data de los años treinta.

En tercer término cabe reseñar la dedicación de Amado Alonso a los nombres del idioma, dedicación que cristalizó en el librito Castellano, español, idioma nacional que public6 en 1938 en el Instituto de Filología de la Facultad de Filosofía y Letras de Buenos Aires. El objetivo científico de la obra lo expresaba el autor con estas palabras nítidas:

He tratado de indagar cuáles han sido y son llos nombres de nuestra lengua] y qué contenido espiritual tienen, qué fisonomía cultural reflejan y qué dirección de anhelos ha instado a los hispanohablantes a preferir uno $u$ otro. 
El presente estudio se subtitula de hecho «Historia espiritual de tres nombres», pues se ocupa efectivamente de los contenidos espirituales que tienen las diferentes designaciones de la lengua; se trata pues de indagar asimismo la noción, emoción y acción que llevan en sí las designaciones léxicas, del mismo modo que tales clases de contenido se encuentran también -según queda vistoen las categorías y construcciones gramaticales.

Amado se propone ahora hacer un estudio léxico y semántico, y tiene en cuenta (como en gramática) que la designación posee un componente logico que puede estar acompañado por otro afectivo o incluso por otro actuativo; en este sentido el librito resulta ejemplar metodologicamente: no aborda sólo referencias logicas, sino que analiza en cada designación su posible contenido emocional o apelativo.

Nuestro autor va haciendo historia del nombre de la lengua, y luego de un capitulillo dedicado al siglo XVIII (la Academia, Mayans), pasa a referirse a «la actualidad»: a Amado parece preocuparle menos el final del Setecientos y todo el siglo XIX, y esto resulta muy característico de la escuela pidalina y por extensión de toda nuestra filología. El testimonio de este libro de Amado Alonso aparecido en las primeras semanas de 1938 es muy revelador; para la tradición de la filología española el grueso del análisis debía estar dedicado a la Edad Media y a los siglos de oro, pues lo posterior a la fundación de la Academia y al llamado Diccionario de Autoridades preocupa menos, y en efecto así vemos que ocurre en un trabajo relevante de un autor relevante y en una fecha de plenitud de la «escuela española».

Ya hemos apuntado otras veces cómo el medievalismo que implicaba una historiografía romántica, la atención nacionalista al pasado áureo o glorioso, etc., fueron factores que llevaron a centrar la gravedad de los estudios filologicos en los tiempos medievales y del Renacimiento y el Barroco. La centuria del Ochocientos se vio descalificada por varias razones (una de ellas los sucesos del 98), y de igual manera quedó un tanto preterida; aún hoy no contamos con la necesaria exposición de conjunto de la historia de la lengua y la historia de las ideas lingüísticas y literarias de los tiempos contemporáneos (y es la tarea a la que en la medida de nuestras fuerzas quisiéramos dedicarnos en adelante).

Ocurre en definitiva que contamos con un bello libro - y no superado en cuanto tal hasta ahora-, en el que Amado hace historia espiritual de las designaciones del idioma, historia que solo se interrumpe con el capítulo de la segunda mitad del XVIII y todo el XIX.

\section{LA TEORIA LINGUUTSTICA Y LA PRONUNCIACIÓN ESPAÑOLA}

Si durante los años treinta Amado se ocupó a la vez del español de América, de cuestiones gramaticales y de las designaciones del idioma, hay una 
cuarta temática que abordó con gran intensidad enseguida: la teoría poética y la crítica literaria; del año 1940 es el libro Poesía y estilo de Pablo Neruda, y de 1942 el Ensayo sobre la novela histórica [y] El modernismo en «La gloria de don Ramiro». Además de los mismos 1940-1942 datan los escritos «Sentimiento e intuición en la lírica», «Clásicos, románticos, superrealistas», «Carta a Alfonso Reyes sobre la estilística», $y$ «La interpretación estilística de los textos literarios», recogidos luego en el volumen póstumo que cuidó Raimundo Lida Materia y forma en poseía.

En realidad también durante toda su vida se ocupó Amado de asuntos literarios, de acuerdo con la concepción unitaria de los estudios filológicos propugnada por la «escuela española»; sin embargo comprobamos cómo intensifico esta dedicación en 1940-1942.

Hemos hablado de seis contenidos temáticos principales en la obra de Amado Alonso, y nos queda reseñar los dos últimos. Uno de ellos fue el de la teoría del lenguaje: escribió así por ejemplo «EI concepto lingüístico de impresionismo» (1936), el «Prefacio» a su traducción de la Filosofía del lenguaje de Vossler, y el «Prólogo a la edición española» del Curso saussureano.

Los aproximadamente siete años últimos de su vida los empeño nuestro autor en una Historia de la pronunciación española que en definitiva ultimaría y cuidaría para la imprenta Rafael Lapesa: De la pronunciación medieval a la moderna en español; fue el último de sus intereses temáticos.

\section{LETRAS E IDEAS}

Por ejemplo el escrito «La interpretación estilística de los textos literarios» reclamaba el estudio de «los valores específicamente poéticos», y ello junto a la tradicional perspectiva filológica: Amado define bien qué es Filología cuando aclara que consiste en «el estudio de todo cuanto es necesario conocer para la recta interpretación de un texto literario", aunque a la vez postula que para el arte y la crítica literaria «un solo aspecto es esencial: el poético y su realización artística».

La obra de arte -insiste nuestro autor- consiste en «una construcción de tipo específico», y la tradicional filología no da lugar (desde esta perspectiva) sino a «estudios auxiliares»:

La estilística estudia la obra literaria como una construcción poetica: ... cómo está construida, formada, hecha, tanto en su conjunto como en sus elementos. 
Resultan necesarias - pues- la filología auxiliarmente, y la estilística como perspectiva fundamental de la crítica artística.

Amado completa sus postulados advirtiendo que el saber estilístico necesita también estudiar los pensamientos y las ideas, aunque considerándolos «como elementos expresivos», en tanto "visión intuicional del mundo y de la vida»: efectivamente así creemos nosotros también que debe hacerse; el estudioso de las letras bellas no ha de ser ajeno al pensamiento que las mismas llevan en sí, aunque ha de considerarse que se trata de un pensamiento que está presente con carácter de expresividad, en cuanto componente coloreado expresivamente. Lo que podemos decir en un tratado de ciencia política o de teología o de moral puede asimismo manifestarse en un discurso literario, aunque expresivamente, es decir, coloreado subjetivamente y de manera connotativa y artística.

«La visión del mundo de un autor» -concluía en este sentido Amado Alonso- resulta «una construcción de base estética», es decir, que nos hallamos ante un contenido de pensamiento aunque puesto de manifiesto de manera estética, expresiva. En general ocurre por tanto que «todo cuanto tenga un valor en la sugestion y contagio, ha de ser estudiado por la estilística», y de esta manera «todo se reduce, como programa, a apoderarse del sistema expresivo de un poema o de un autor»; entre lo expresivo de un autor se cuenta - según queda dicho- su pensamiento.

\section{Salvador Fernández. José F. Montesinos}

Don Salvador Fernández Ramírez publicó un artículo sobre «Forma y sustancia líricas» (en el volumen colectivo de 1967 de la Universidad Intemacional Menéndez Pelayo Elementos formales en la lírica actual), pero este trabajo no posee acaso un especial alcance; él sobre todo fue nuestro más grande gramático, y en este sentido contamos - según se sabe - con el tomo primero de la Gramática Española. Los sonidos. El nombre y el pronombre (1951), y con el otro tomo póstumo ordenado y completado por I. Bosque Gramática Española. El verbo y la oración (1986).

Por su lado José Fernández Montesinos se dedico enteramente a los estudios literarios. Con anterioridad a la guerra civil Montesinos edit6 a Lope y a los Valdés, pero no se ocupó sólo de cuestiones lopeveguescas o del erasmismo español; ello puede verse en los datos bibliográficos y los testimonios y los textos que aparecen en el bello volumen misceláneo Ensayos y estudios de literatura española que le publicó en segunda edición en 1970 la Editorial «Revista de Occidente». 
Montesinos edito entre otras cosas la lírica de Lope, y de esta manera seleccionó poemas que produjeron gran impresión en los creadores jóvenes del Veintisiete; en alguno de sus escritos él ha recordado y reivindicado el papel que tuvieron sus dos tomitos de poesía lírica de Lope de Vega:

La palma -dice-, entonces como siempre, fue para los creadores. Y los creadores fueron Federico García Lorca, Rafael Alberti, con otros... Ellos tomaron de la mano a Lope y lo volvieron a acercar al español de hoy, en versos que a veces suenan a Lope mismo... Pero... antes había venido yo, que no había escrito versos lopescos ni de otra especie, pero había sacado a luz aquellos de Lope que mi generación mejor podía entender.

Las antologías lopeveguescas que hizo nuestro crítico debieron cumplir efectivamente un papel de incitación, y Montesinos lo reclama como un dato de la historia literaria del grupo del Veintisiete; de la misma manera el crítico ha recordado el análogo papel que cumplió entonces -asimismo en Lorca, en Alberti,...-, el Cancionero de los siglos XV y XVI de Barbieri.

En cuanto a los autores del erasmismo español, nuestro autor puso a disposición del lector sucesivamente el Diálogo de la lengua, el Diálogo de las cosas ocurridas en Roma, el Diálogo de Mercurio y Carón, y unas Cartas inéditas de Juan de Valdés al cardenal Gonzaga; el último de los presentes volúmenes, editado por el Centro de Estudios Históricos en 1931, lleva una amplia «Introducción» erudita; en realidad las cuatro respectivas Introducciones a estos volúmenes son más bien eruditas que de análisis teórico-crítico.

No sólo a Lope o los Valdés - hemos dicho- dedicó su interés o su trabajo Montesinos antes de la guerra; incluso hace no muchos años Antonio Gallego Morell ha publicado un estudio en torno a El renacimiento cultural de la Granada contemporánea. Los "Viajes pedagógicos" de Berrueta (Granada, 1989), en el que se editan unos «Comentarios e impresiones» del estudiante José Fernández Montesinos.

\section{EN FAVOR DE LA FILOLOGTA}

Montesinos ha declarado que «casi nada» pudo escribir de 1936 a 1946 , los años tan llenos de sufrimiento de la guerra española y luego la guerra mundial; recuérdese por ejemplo que era hermano de Manuel Fernández Montesinos, el marido de Concha García Lorca que fue fusilado en Granada al inicio de la contienda civil. 
Rehecha la vida tras las guerras, don José Montesinos reunió sus páginas lopeveguescas en los Estudios sobre Lope de Vega (1951 y 1967, segunda ed.), así como escritos diversos en los mencionados Ensayos y estudios de literatura española (1959 y 1970). Los Estudios sobre Lope de Vega, que aún tuvieron una reimpresión en 1969, constituyen un útil volumen, y a la «Carta-Prólogo» que los encabeza en 1967 pertenecen las afirmaciones que hemos transcrito en tomo a la huella que algunas de estas páginas dejaron en su día en los poetas jóvenes del Veintisiete, al igual que la dejo el Cancionero de Barbieri.

A su vez los Ensayos y estudios... tienen otra «Carta-Prólogo» a la primera edición que constituye un bello texto testimonial. Nuestro autor reconoce en Américo Castro a su maestro y «segundo padre», y a quien le llevo al estudio de Lope; sobre todo sin embargo Montesinos evoca a Ortega, cuya orientación le dirigía a la filología y el historicismo más que a «un formalismo crítico» que en cuanto tal y sin más parece despertarle reservas (y en este sentido don José Montesinos esboza una reserva hacia los criterios de Amado Alonso).

Señala nuestro autor que había aprendido de Ortega que el arte español muestra «el camino hacia una inteligencia plena y un desentrañamiento de lo mejor y más auténtico de nuestro espíritu, para llegar al conocimiento de nosotros mismos», pero sobre todo insiste en como la orientación orteguiana le enseñaba a librarse filológicamente «de generalizaciones y ligerezas». Montesinos reconstruye el aprendizaje que le venía del pensador madrileño:

Ortega nos enseñaba que la historia de las ciencias y disciplinas del espíritu no podía ser otra cosa que alta sociologia... El que escribe se dirige a un público, y las apetencias de ese público condicionan su obra... Hacer historia literaria era hacer sociologia literaria... Había que volver a la erudición.

Resulta insoslayable así una sólida preparación filológica y erudita, para que el tiempo histórico no se escamotease en el estudio; esto es lo que Montesinos proclama en tanto programa de análisis, a la par que le atribuye una filiación orteguiana.

Erudición y sociología ciertamente es lo que encierra el magno ciclo de nueve volúmenes que nuestro autor alzó en los lustros últimos de su vida: nos referimos a los «Estudios sobre la novela española del siglo XIX».

La presente serie posee dos volúmenes de carácter general, la Introducción a una historia de la novela en España en el siglo XIX y Costumbrismo y novela; las sucesivas monografías aparecen dedicadas a Alarcón, Valera, Fernán Caballero, Pereda y Galdós. Quizá nada más quedó por escribir el volumen 
galdosiano dedicado a «Ángel Guerra», «Misericordia», las novelas de «Torquemada», etc.

Muchas veces se insiste en la legitimidad del formalismo crítico, en la consistencia en sí de la obra literaria, etc.; aunque por supuesto lo estético es específico y de carácter formal, no cabe desconocer lo que por su parte vemos que subrayaba Montesinos: la ineluctabilidad de la perspectiva filológica y de la atención al tiempo histórico.

ESPAÑA Y LA NOVELA

Nuestro autor ha advertido algo respecto a España y la novela que enunció en la mencionada Introducción a una historia...: para Montesinos ocurre que «la novela se le escapa a España literalmente de las manos», y se mostrará fecunda en cambio más allá de nuestras fronteras; aquí operan en contra dos rémoras, a saber, "preocupaciones morales que la desvirtúan y falsean, y la boga de un estilo de prosa el menos apto para la narración y el diálogo que pueda imaginarse».

Ocurre por tanto que la novela decae entre nosotros desde mitad del XVII y durante el XVIII: antes se nos ha escapado de las manos, entre otras causas -según apunta nuestro autor- debido a la vigencia del estilo de prosa conceptista (interpretamos que esto es lo que sugiere Montesinos), que no resulta apto para la narración; de ahí por ejemplo que la crítica estime que el Buscón constituye una pésima novela.

Asimismo «una mortal flora parásita de moralidades» llena la novela corta del Seiscientos, y unas cosas y causas y otras llevan a la desaparición de la novela en el XVII español.

Llegará sin embargo el Ochocientos, y aunque en fechas tardías del mismo - proclama don José Montesinos- «no se encuentra... a cada triquitraque por esas literaturas de Dios... lo mejor de Galdós, y aun de Clarín o la Pardo Bazán», ahí quedan sus libros, «cada día más vigentes».

\section{REFLEXIÓN}

Amado y Montesinos son autores de propuestas contrarias, aunque no contradictorias: para el primero importa auxiliarmente lo filológico, mientras lo artístico específico es lo fundamental; el segundo subraya sin embargo la hechura histórica y sociologica del texto literario. 
Creemos que nunca se había advertido esta contraposición, que en realidad queda atenuada si observamos que Amado no desdeña el contenido de la obra en cuanto es un contenido expresado artísticamente; en todo caso no estamos ante perspectivas contradictorias.

Lo estético o poético es específico y formal, y no cabe desconocerlo, pero a la vez los textos no son nunca mudos ni vienen del limbo: el discurso literario lleva en sí connotativamente una sustancia del contenido, es decir, algo real que queda designado, si bien tal designación está hecha por medio de lo artístico, por el procedimiento de un todo de formas connotadoras.

La labor histórico-crítica de don José Montesinos ha pasado un tanto desapercibida en cuanto tal: se conocen sus ediciones y varias de sus monografías, pero no se le suele recordar en la trayectoria de la crítica. Además de lopista y de estudioso de los hermanos Valdés, nos ha dejado una serie bella e imprescindible sobre la novela del XIX, y de manera implícita o más expresa, se encuentran en sus escritos criterios para el análisis que la historiografía de las ideas literarias debe recordar.

Montesinos forma parte -con relieve propio— de la «Edad de Plata» de nuestra cultura, el trozo del pasado español impregnado de espíritu liberal y de la ética del krausismo, que nosotros creemos - junto con los tiempos del erasmismo- que está en lo mejor de la historia de España.

[En pruebas podemos añadir la edición póstuma -a cargo de P. Álvarez de Miranda-,de un libro y un artículo de Montesinos, a saber: Entre Renacimiento y Barroco, Granada, Comares, 1997; «Coloma», Voz y Letra, 1995 (aparece en 1997)]. 